06

\title{
Фазовый состав, макро- и микроструктуры квазикристаллических порошков плазмохимического синтеза
}

\author{
() И.В. Карпов, ${ }^{1,3}$ А.В. Ушаков,,$^{1,3}$ А.А. Лепешев, ${ }^{1,2}$ Л.Ю. Федоров, ${ }^{1}$ В.Г. Дёмин, ${ }^{1}$ \\ A.А. Шайхадинов, ${ }^{1}$ Е.А. Дорожкина, ${ }^{3}$ О.Н. Карпова ${ }^{3}$ \\ ${ }^{1}$ Сибирский федеральный университет, \\ 660041 Красноярск, Россия \\ ${ }^{2}$ Красноярский научный центр Сибирского отделения РАН, \\ Красноярск, Россия \\ ${ }^{3}$ Сибирский государственный аэрокосмический университет им. акад. М.Ф. Решетнева, \\ 660037 Красноярск, Россия \\ e-mail: sfu-unesco@mail.ru
}

(Поступило в Редакцию 20 октября 2016 г.)

Впервые методом плазмохимического синтеза получены квазикристаллические порошки системы $\mathrm{Al}_{65} \mathrm{Cu}_{23} \mathrm{Fe}_{12}$. Порошки имеют сферическую форму с неоднородной структурой, обусловленной пластинчатым прорастанием кристаллитов на поверхность частицы. Исследовано влияние термической обработки на процессы фазо- и структурообразований в $\mathrm{Al}-\mathrm{Cu}-\mathrm{Fe}-$ сплавах. Установлено, что термическая обработка исходных порошков приводит к изменению соотношения фаз в квазикристаллическом сплаве.

DOI: 10.21883/JTF.2017.05.44448.2071

\section{Введение}

К квазипериодическим кристаллам (квазикристаллам) относят твердотельные фазы с хорошо упорядоченной, но апериодической структурой с классически запрещенной круговой симметрией - наличием осей пятого и десятого порядков. Особенности такой структуры во многом предопределяют ряд необычных и привлекательных с точки зрения практического применения свойств: трибологических, антифрикционных, оптических, каталитических и др. [1-4]. С учетом этого также следует отметить перспективность использования квазикристаллов в качестве добавок упрочняющей фазы при создании новых композиционных материалов [5-7].

Методы получения квазикристаллических сплавов весьма разнообразны и в зависимости от поставленных технологических задач включают: различные способы закалки из жидкого состояния (разливка на диск, литье в валки, газовая атомизация и др.) [8-12], механоактивационное сплавление, разнообразные виды напыления (плазменное, детонационное, магнетронное и др.).

Реализация плазменных технологических процессов в вакууме открывает качественно новые возможности в технологии получения порошков и композитов на их основе [13-16]. Изменение энергии частиц в процессе конденсации позволит получать различные структуры конкретного материала от аморфных до кристаллических, при этом размеры, форма кристаллов меняются в зависимости от энергии $[17,18]$. Из всего многообразия плазменных технологических процессов распыления металлов в вакууме на наш взгляд наиболее перспективным является использование импульсных дуговых разрядов, позволяющее относительно просто изменять энергию и длительность импульса, а также частоту повторения импульсов, что дает широкие возможности для выбора вида испаряемых материалов и управление производительностью метода [19-21]. Расширение в газ низкого давления позволяет получить высокие скорости расширения, обеспечивающие быстрое снижение концентрации паров и получение частиц малых размеров. При этом наличие газа позволяет осуществлять достаточно быстрое охлаждение - закалку частиц порошка за счет не только радиационного как в вакууме, но и молекулярного механизма теплообмена.

Целью настоящей работы являются исследования, направленные на выбор оптимального химического состава лигатуры $\mathrm{Al}_{65} \mathrm{Cu}_{23} \mathrm{Fe}_{12}$ сплава, изучение его фазового состава, макро- и микроструктур, а также изучение влияния термической обработки на процессы фазо- и структурообразований в $\mathrm{Al}_{65} \mathrm{Cu}_{23} \mathrm{Fe}_{12}$ сплавах. Важность таких исследований очевидна, поскольку они позволят определить основные фазы квазикристаллической системы, характер их изменения и область температурной стабильности икосаэдрической фазы.

\section{Методика эксперимента}

Порошки квазикристаллического сплава системы $\mathrm{Al}_{65} \mathrm{Cu}_{23} \mathrm{Fe}_{12}$ получали следующим образом. Исходные порошки алюминия (99.999), меди (99.99) железа (99.99), взятые в соотношении компонентов, непосредственно соответствующем области существования квазикристаллической фазы сплава системы $\mathrm{Al}_{65} \mathrm{Cu}_{23} \mathrm{Fe}_{12}$, помещаются в барабанный смеситель и перемешиваются в течение 20-30 min. Полученная шихта засыпается в алундовый тигель. Расплавление шихты осуществляется в вакуумной индукционной печи при давлении $10-15 \mathrm{~Pa}$. Полученную отливку охлаждали в тигле до комнатной температуры. 
Далее тигель, который является одновременно катодом, устанавливается в вакуумную камеру, корпус которой, а также поверхность электропроводного оборудования в ней являются анодом. Корпус вакуумной камеры также снабжен системой термостатирования, вакуумной системой, системой подачи инертного газа, например аргона, вакуумными уплотнительными вводами и выводами.

После достижения в вакуумной камере низкого давления $10^{-3} \mathrm{~Pa}$ при помощи системы газонапуска устанавливается давление газа аргона 100-200 Ра. Включается блок электропитания. Величина тока дежурной дуги выбрана до $3 \mathrm{kA}$ - необходимой для поддержания устойчивого дугового разряда. В результате загорания дежурной дуги пространство между катодом и анодом оказывается ионизованным, что облегчает зажигание импульсной сильноточной дуги. Импульсный дуговой разряд с частотой и длительностью импульса поддерживается при помощи блока электропитания. Расплавление шихты системы $\mathrm{Al}-\mathrm{Cu}-\mathrm{Fe}$ и ее диспергирование в макрокапли происходят в алундовом тигле. Полученные капли поступают в плотную эрозионную плазму катодного пятна. В результате все капли заряжаются и нагреваются вследствие столкновений с электронами, как минимум, до критической величины начала их каскадного деления за время их пролета в плазме катодного пятна. Полученные частицы $\mathrm{Al}-\mathrm{Cu}-\mathrm{Fe}$-материала охлаждаются до затвердевания в быстро расширяющейся плазме катодного пятна и в плазме межэлектродного разряда за время около $10^{-7} \mathrm{~s}$, что приводит к формированию квазикристаллической структуры.

В процессе испарения материала в дуговом разряде поток квазикристаллических частиц поступает на вращаюшуюся охлаждаемую поверхность конденсации, осаждается на ней и в виде порошка снимается скребком. Полученный порошок собирается в бункере.

Исследование микроструктуры и элементного состава фаз на различных этапах изготовления образцов осуществляли на растровом электронном микроскопе JEOL JSM 7001F с системой микроанализаторов Oxford Instruments.

Исследование фазового состава полученных образцов проводили с помощью рентгеновского дифрактометра Advance D8 в $\mathrm{Cu} K_{\alpha}$-монохроматизированном излучении.

Ранее уже отмечалось [11], что наличие и доля квазикристаллической фазы существенно зависят от химического состава, условий получения, дисперсности исходного порошка. Поэтому представляется необходимым определение температурных областей формирования квазикристаллической фазы и ее максимальной стабильности. С этой целью исходные порошки квазикристаллического сплава $\mathrm{Al}-\mathrm{Cu}-\mathrm{Fe}$ дисперсности 10-50 $\mu$ m подвергались термообработке.

Для предотвращения окисления термообработка исходных порошков происходила в атмосфере инертного газа аргона. Квазикристаллические порошки помещались в нагретую до заданной температуры печь на алундовых лодочках. Образцы подвергались термическому воздействию в интервале температур $450-850^{\circ} \mathrm{C}$ и отдельно при $1000^{\circ} \mathrm{C}$ в течение $1 \mathrm{~h} \mathrm{c}$ шагом $100^{\circ} \mathrm{C}$.

\section{Результаты и обсуждение}

Рассмотрим морфологические особенности исходных порошков заданного состава $\mathrm{Al}_{65} \mathrm{Cu}_{23} \mathrm{Fe}_{12}$, полученных методом электродугового диспергирования. Электронномикроскопические исследования исходных порошков приведены на рис. 1.

Из рисунка видно, что частицы порошка всех размерных фракций имеют сферическую форму. Вместе с тем наблюдается группа округлых частиц размером меньше $10 \mu \mathrm{m}$, которые либо спаяны с основной частицей, либо находятся отдельно. Происхождение этой группы частиц, скорее всего, вызвано технологическими особенностями разбрызгивания расплава.

При детальном рассмотрении электронно-микроскопических снимков было обнаружено неоднородное строение поверхности исследуемых частиц (рис. 2). Эта неоднородность обусловлена пластинчатым прорастанием кристаллитов на поверхность частицы. Среди них можно обнаружить хорошо ограненные кристаллографические фазы различной симметрии. Предположения о прорастании кристаллитов на поверхности частиц в полной мере подтверждается результатами исследований шлифов поперечных сечений исходных порошков (рис. 3).

На протравленной после полировки поверхности хорошо различаются протяженные, как правило, радиально направленные кристаллиты, выходящие на поверхность частицы. Замечено, что морфологическая картина модифицируется с изменением размера частиц. Если для мелких частиц порядка $10 \mu \mathrm{m}$ характерна в большей степени ячеистая структура, то для больших порядка $50 \mu \mathrm{m}$ частиц наблюдается хорошо развитая дендритно-пластинчатая структура.

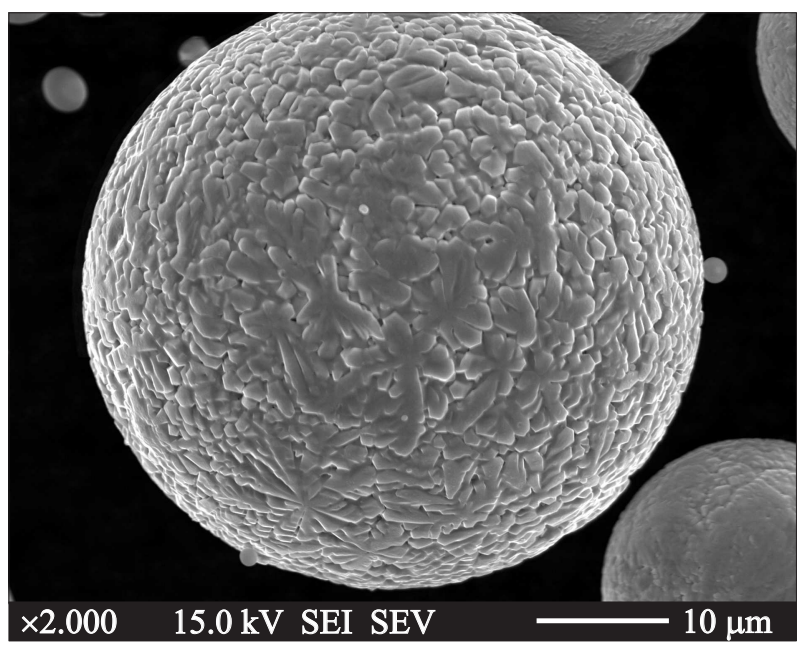

Рис. 1. Морфология исходных квазикристаллических частиц сплава $\mathrm{Al}_{65} \mathrm{Cu}_{23} \mathrm{Fe}_{12}$. 


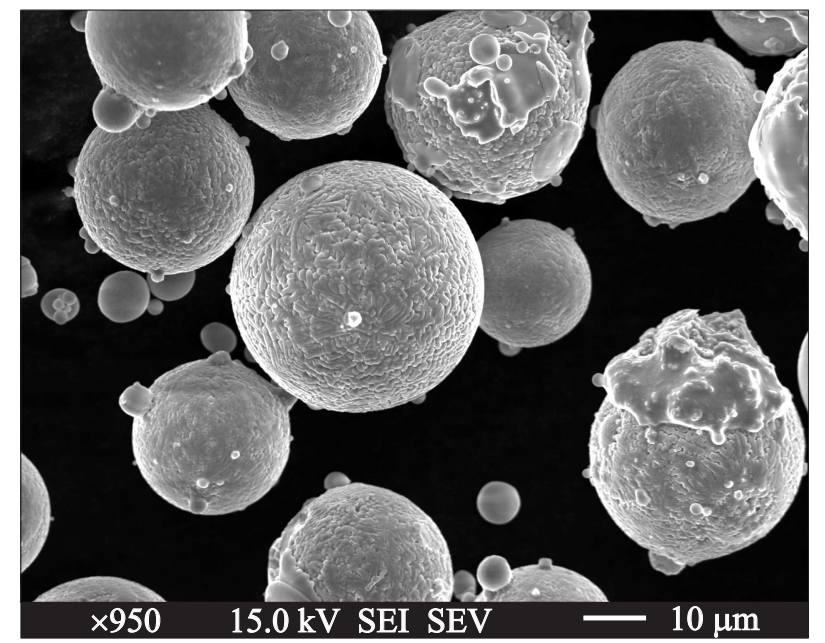

Рис. 2. Неоднородное строение поверхности квазикристаллических частиц сплава $\mathrm{Al}_{65} \mathrm{Cu}_{23} \mathrm{Fe}_{12}$.

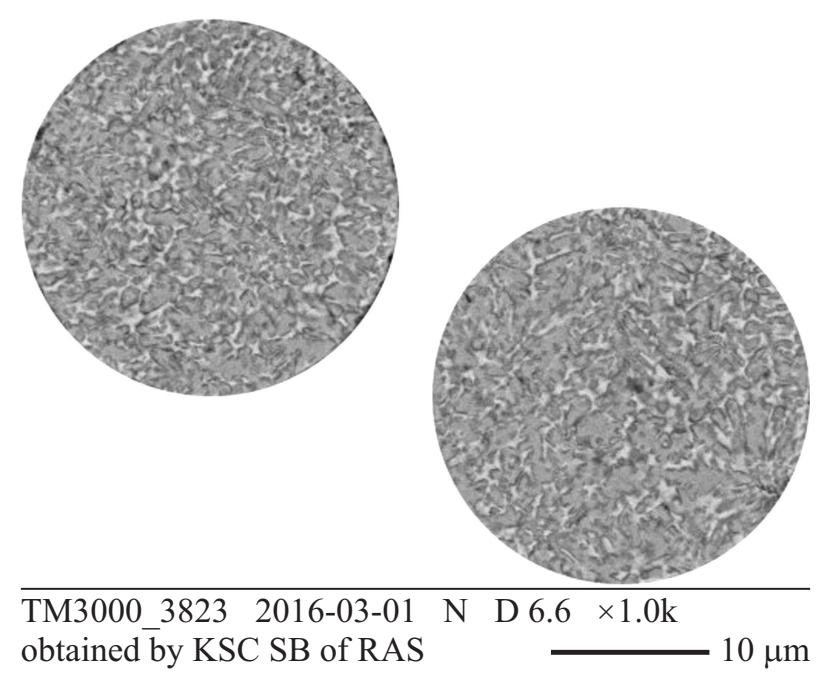

Рис. 3. Морфология исходных квазикристаллических частиц сплава $\mathrm{Al}_{65} \mathrm{Cu}_{23} \mathrm{Fe}_{12}$.

Поскольку охлаждение исходных частиц, а следовательно, и кристаллизация происходили снаружи, микроструктура кристаллитов является центральноориентированной.

Определение фазового состава исходных квазикристаллических порошков обычными количественными методами с использованием данных рентгенофазового анализа представляет определенные трудности, связанные с незнанием атомных позиций икосаэдрической фазы. Поэтому для выявления соотношения фаз в исследуемых порошках квазикристаллического сплава $\mathrm{Al}-\mathrm{Cu}-\mathrm{Fe}$ были использованы результаты, полученные в работе [22]. Авторами данной работы была установлена зависимость соотношения интенсивностей икосаэдрического и кубического пиков $\psi(422222) / \beta(110)$ от весового содержания икосаэдрической фазы в порошках системы
$\mathrm{Al}-\mathrm{Cu}-\mathrm{Fe}$. Графическое изображение этой зависимости показано на рис. 4.

Рентгенограмма исходного порошка фракции $10-50 \mu \mathrm{m}$ приведена на рис. 5. Картина рентгеновской дифракции исследуемого сплава представляет суперпозицию пиков различной интенсивности, причем наиболее интенсивные пики находятся в области углов $2 \theta 42$ и $46 \mathrm{deg}$ и соответствуют икосаэдрической $\psi(422222,420024)$ и кубической $\beta(110)$ фазам.

Весовое содержание икосаэдрической фазы в порошках было рассчитано с использованием данных рентгенофазового анализа (рис. 5) и зависимости, представленной на рис. 4. Оказалось, что доля икосаэдрической фазы в исходных порошках размерной фракции 10-50 $\mu \mathrm{m}$ составляет $68 \%$.

Ранее было уже показано, что изменение химического состава распыленных порошков зависит от их фракционного состава. Поэтому были проведены исследования

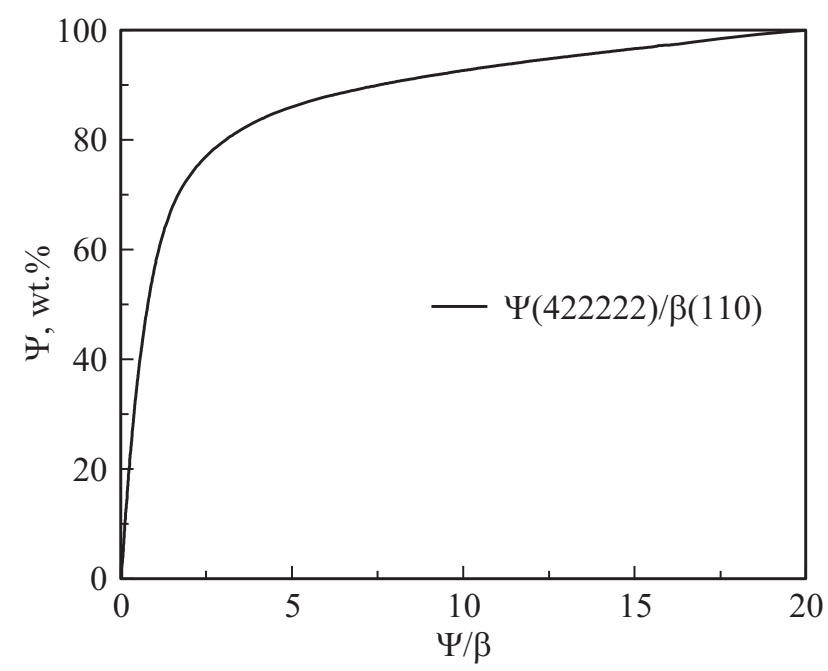

Рис. 4. Зависимость весового содержания $\psi$ фазы от интенсивности соответствующих пиков $\psi / \beta$ икосаэдрической и кубической фаз.

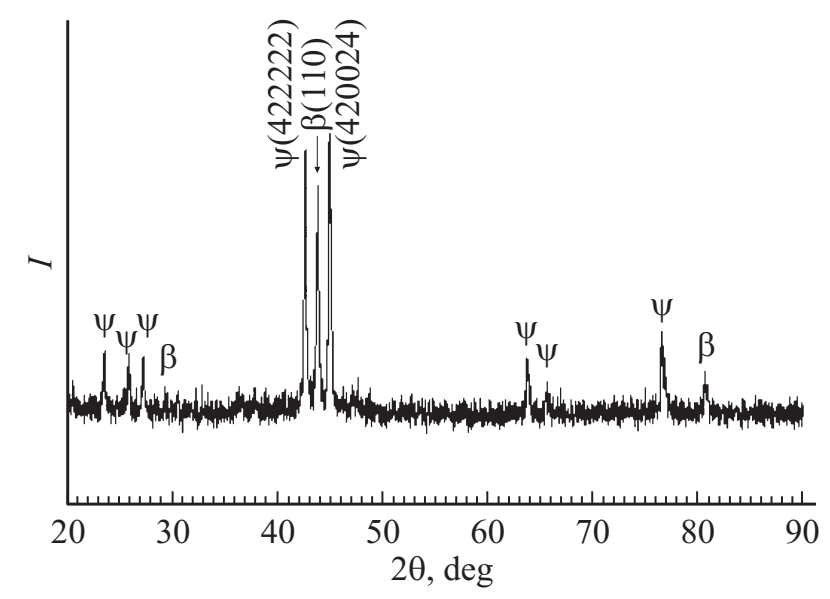

Рис. 5. Рентгенограмма исходного порошка фракции $15-35 \mu \mathrm{m}$. 


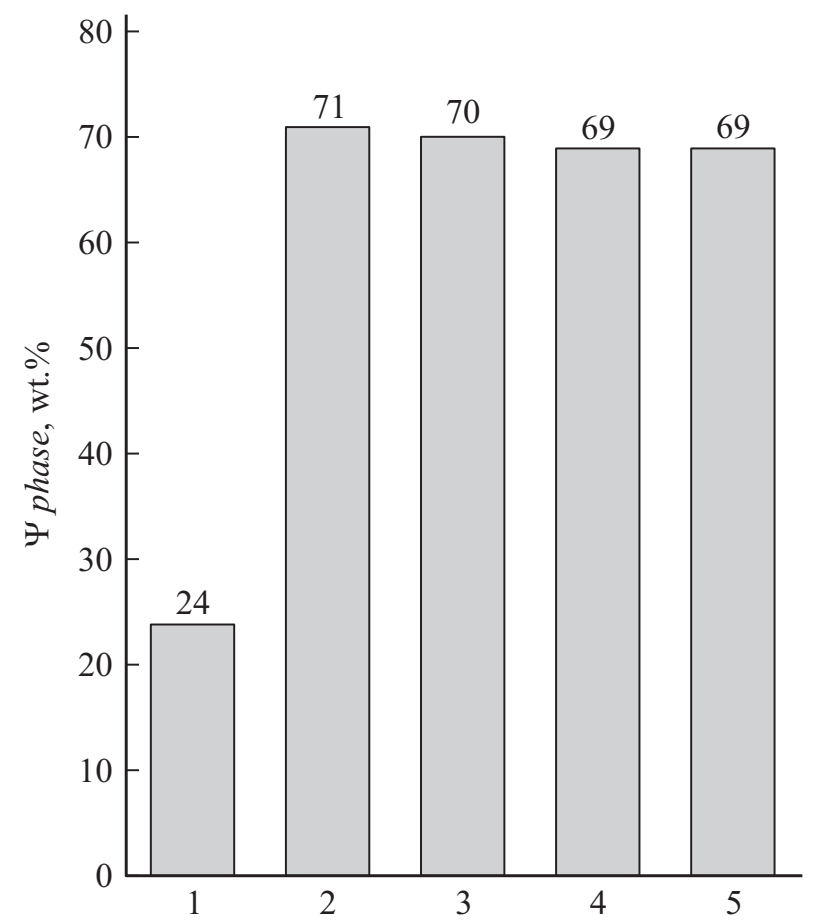

Рис. 6. Доля икосаэдрической фазы в распыленных порошках различных размерных фракций: $1-25,2-25+45,3-$ $53+63,4-45+75,5-75+106 \mu \mathrm{m}$.

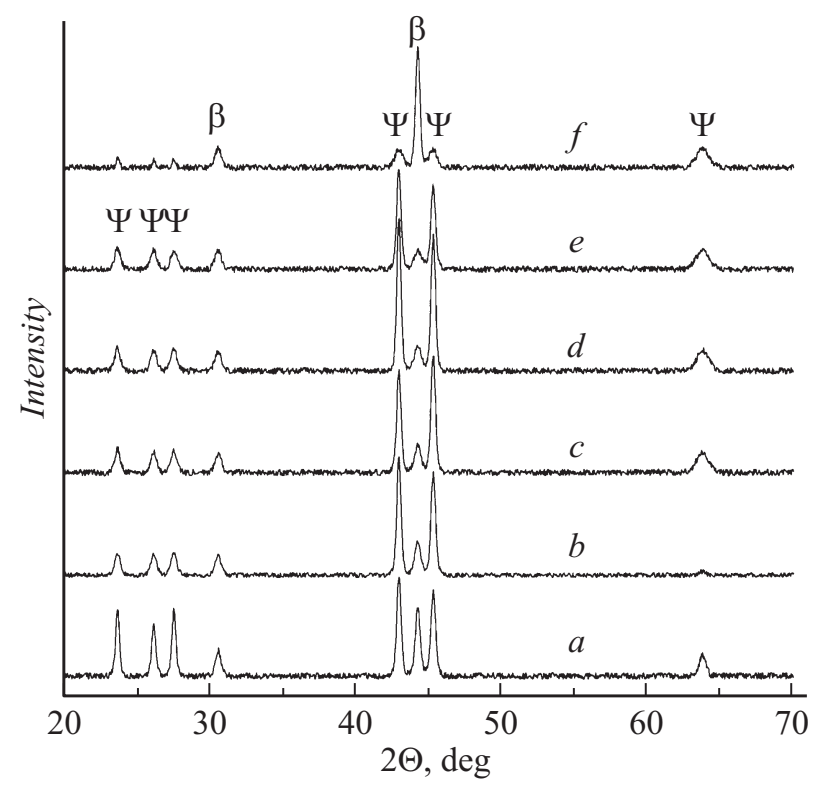

Рис. 7. Рентгенограммы термообработанных квазикристаллических порошков $\mathrm{Al}_{65} \mathrm{Cu}_{23} \mathrm{Fe}_{12}$ при температурах: $a-450, b-$ $550, c-650, d-750, e-850, f-1000^{\circ} \mathrm{C}$.

фазового состава распыленных порошков различной дисперсности. Результаты таких исследований приводятся на рис. 6.

Видно, что уменьшение фракционного состава и снижение доли Al в исходном химическом составе сплава (фракция $25 \mu \mathrm{m})$ приводит к увеличению кубиче- ской фазы и уменьшению доли икосаэдрической фазы до $24 \%$ в распыленных порошках. В то же время для фракционного состава $25-35 \mu \mathrm{m}$ и выше изменение фазового состава по отношению к исходным порошкам практически не наблюдается. Полученные результаты свидетельствуют о том, что даже в области устойчивого треугольника фазовой диаграммы изменение химического состава сплава приводит к существенному изменению соотношения фаз в сплаве.

Для выявления возможных структурных изменений в порошках, подвергнутых термическому воздействию, использовался метод рентгенофазового анализа. Рентгенограммы термообработанных порошков приведены на рис. 7.

Видно, что температурные режимы термической обработки порошков приводят к существенной модификации картины спектров. Так, наряду с изменением интенсивностей пиков, соответствующих икосаэдрической и кубической фазам, наблюдается видоизменение формы линий и появление незначительного количества новых фаз. Например, при температурах термообработки порошков $550^{\circ} \mathrm{C}$ и $650^{\circ} \mathrm{C}$ появляются дополнительные фазы, рефлексы которых соответствуют углам $2 \theta 40$ и $45.65 \mathrm{deg}$. Новые фазы, по-видимому, можно отнести к тетрагональной $\mathrm{Al}_{2} \mathrm{Cu}$ или моноклинной $\mathrm{Al}_{13} \mathrm{Fe}_{4}$ фазам, которые часто встречаются в тройной квазикристаллической системе $\mathrm{Al}-\mathrm{Cu}-\mathrm{Fe}$. Образующиеся фазы являются неустойчивыми и при повышении температуры $\left(T>650^{\circ} \mathrm{C}\right)$ полностью исчезают.

При заданных режимах термообработки $\left(550-650^{\circ} \mathrm{C}\right)$ наряду с появлением новых фаз замечены видоизменение и смещение вправо от угла $2 \theta 44 \mathrm{deg}$ линии, соответствующей кубической фазе. Такое смещение линии спектра, вероятно, связано с изменением параметра кубической решетки при термическом воздействии. Следует отметить, что в данном диапазоне температур

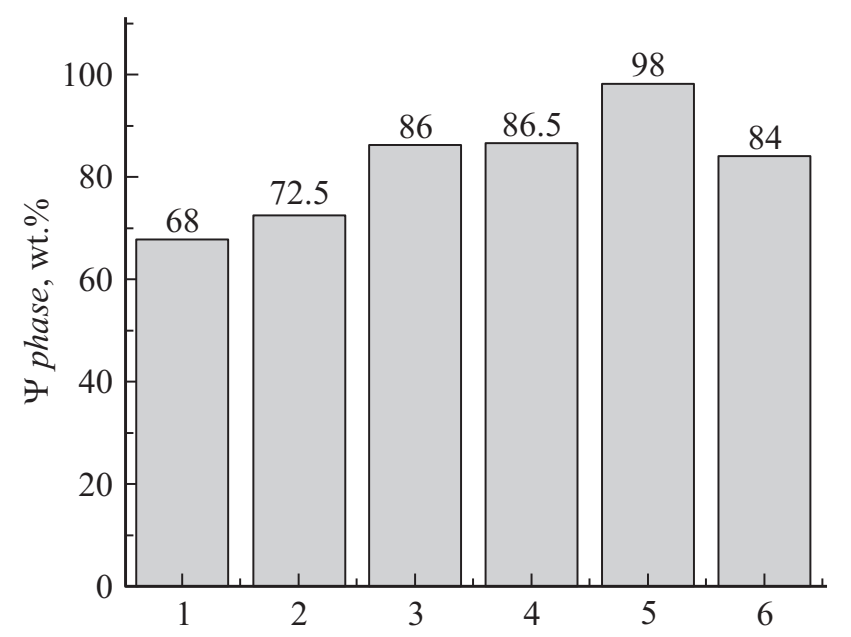

Рис. 8. Весовое содержание икосаэдрической фазы в термообработанных порошках квазикристаллической фазы $\mathrm{Al}_{65} \mathrm{Cu}_{23} \mathrm{Fe}_{12} .1$ - исходный порошок, после термообработки: при температурах $2-450,3-550,4-650,5-750,6-$ $850^{\circ} \mathrm{C}$. 
не происходит каких-либо изменений положения линий, относящихся к икосаэдрической фазе. Последующее повышение температуры термообработки не приводит к образованию новых фаз и какому-либо изменению положения линий дифракционного спектра.

По соотношению основных пиков интенсивности икосаэдрической $\psi$ и кубической $\beta$ фаз, лежащих в пределах углов $2 \theta 42$ и $45 \mathrm{deg}$, в термообработанных порошках было определено весовое содержание икосаэдрической фазы по отношению к кубической. Результаты таких расчетов приведены на рис. 8 .

Видно, что термическая обработка исходных порошков приводит к изменению соотношения фаз в квазикристаллическом сплаве $\mathrm{Al}-\mathrm{Cu}-\mathrm{Fe}$. Так, начиная уже с $T=450^{\circ} \mathrm{C}$, происходит постепенное уменьшение доли кубической фазы (возрастание доли квазикристаллической фазы) вплоть до ее полного исчезновения при $T-750^{\circ} \mathrm{C}$. Дальнейшее повышение температуры термоотжига вплоть до температуры плавления приводит к повышению доли кубической фазы. На рентгенограмме термообработанного при $T=1000^{\circ} \mathrm{C}$ порошка хорошо видно, что данный температурный режим приводит к почти полному исчезновению икосаэдрической фазы и формированию структуры, состоящей из кубической

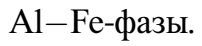

\section{Заключение}

Распыление квазикристаллического сплава системы $\mathrm{Al}_{63} \mathrm{Cu}_{25} \mathrm{Fe}_{12}$ в плазмохимическом реакторе позволяет получать частицы размером $1-50 \mu \mathrm{m}$ с явно выраженной дендритно-пластинчатой структурой. При этом доля икосаэдрической фазы составляет до 68\%. Термическая обработка сплава $\mathrm{Al}_{63} \mathrm{Cu}_{25} \mathrm{Fe}_{12}$ в течение $1 \mathrm{~h}$ в области температур $700-750^{\circ} \mathrm{C}$ с последующим охлаждением приводит к перераспределению кристаллических фаз в сплаве и увеличению доли икосаэдрической фазы по отношению к кубической до максимального значения. Следует также отметить, что в данной области температур распределение фаз является равновесным и стабильным.

Исследование выполнено при финансовой поддержке Российского фонда фундаментальных исследований проект № 16-48-242101/16, Правительства Красноярского края, Красноярского краевого фонда поддержки научной и научно-технической деятельности в рамках научного проекта № 03/16.

\section{Список литературы}

[1] Kang S.S., Dubois J.M., von Stebut J. // J. Mater. Res. 1993. Vol. 8. N 10. P. 2471-2481.

[2] Besser M.F., Eisenhammer J. // MRS Bull. 1997. Vol. 22. N 11. P. 59-63.

[3] Носкова Н.И., Пономарева Е.Г. // ФММ. 1994. Т. 78. С. 34.

[4] Bloom P.D., Baikerikar R.G., Otaigbe J.V., Sheares V.V. // Mater. Sci. Eng. A. 2000. Vol. 294-296. P. 156-159.
[5] Koster U., Liu W., Leibertz H., Michel M. // J. Non-Cryst. Sol. 1993. Vol. 153-154. P. 446-452.

[6] Tsai A.P., Aoki K., Inoue A., Masumoto T. // J. Mater. Res. 1993. Vol. 8. N 1. P. 5-7.

[7] Anderson B.C., Bloom P.D., Baikerikar R.G. // Biomaterials. 2002. Vol. 23. N 8. P. 1761-1768.

[8] Sordelet D.J., Kramer M.J., Unal O. // J. Thermal Spray Tech. 1995. Vol. 4. N 3. P. 235-244.

[9] Sordelet D.J., Rozhkova E.A., Besser M.F., Kramer M.J. // Intermetfllics. 2002. Vol. 10. N 11-12. P. 1233-1240.

[10] Sordelet D.J., Rozhkova E.A., Besser M.F., Kramer M.J. // Appl. Phys. Lett. 2002. Vol. 80. P. 4735.

[11] Лепешев А.А., Баюков О.А., Рожкова Е.А., Карпов И.В., Ушаков А.В., Федоров Л.Ю. // ФТТ. 2015. Т. 57. Вып. 2. C. $243-247$.

[12] Лепешев А.А., Рожкова Е.А., Карпов И.В., Ушаков А.В., Федоров Л.Ю. // ФТТ. 2013. Т. 55. Вып. 12. С. 2406-2411.

[13] Ushakov A.V., Karpov I.V., Lepeshev A.A., Petrov M.I. // J. Appl. Phys. 2015. Vol. 118. P. 023907.

[14] Lepeshev A.A., Karpov I.V., Ushakov A.V., Nagibin G.E. // J. of Alloys and Compounds. 2016. Vol. 663. P. 631-635.

[15] Lepeshev A.A., Karpov I.V., Ushakov A.V., Fedorov L.Yu., Shaikhadinov A.A. // Intern. J. of Nanosc. 2016. Vol. 15. P. 1550027.

[16] Karpov I.V., Ushakov A.V., Lepeshev A.A., Zharkov S.M. // Vacuum. 2016. Vol. 128. P. 123-127.

[17] Ушаков А.В., Карпов И.В., Лепешев А.А. // ФТТ. 2015. Т. 57. Вып. 11. С. 2251-2253.

[18] Ушаков А.В., Карпов И.В., Федоров Л.Ю., Лепешев А.А. // Трение и износ. 2014. Т. 35. Вып. 1. С. 12-17.

[19] Федоров Л.Ю., Карпов И.В., Ушаков А.В., Лепешев А.А. // Неорган. матер. 2015. Т. 51. Вып. 1. С. 1-5.

[20] Ушаков А.В., Карпов И.В., Лепешев А.А., Федоров Л.Ю., Шайхадинов А.А. // ЖТФ. 2016. Т. 86. Вып. 1. С. 105-109.

[21] Ушаков А.В., Карпов И.В., Лепешев А.А., Федоров Л.Ю., Шайхадинов А.А. // ЖТФ. 2016. Т. 86. Вып. 2. С. 105-109.

[22] Ebalard S., Spaepen F. // J. Mater. Res. 1989. Vol. 4. N 1. P. $39-43$. 